\title{
Pain assessment in children with cancer: a systematic review
}

\author{
Avaliação da dor em crianças com cancro: uma revisão sistemática \\ Evaluación del dolor en niños con cáncer: una revisión sistemática \\ Luís Manuel Cunha Batalha*; Ananda Maria Fernandes***; Catarina de Campos****; \\ Ana Maria Pacheco Mendes Perdigão Costa Gonçalves*****
}

\begin{abstract}
Background: The peculiarities of persistent pain in children with cancer make its assessment difficult.

Aim: The aim was to identify persistent pain assessment tools and indicators related to this experience that have been used in children with cancer.

Method of Review: Using Medline and CINAHL databases, primary studies between 2003 and 2013 assessing pain experience in children (0-18 years) with cancer were selected. The selection of studies, assessment of methodological quality, and data extraction and synthesis were performed by two researchers, following the guidelines of Joanna Briggs Institute.

Presentation and Interpretation of results: Out of the 16 selected studies, 15 pain assessment tools and 2 tools also assessing other indicators were identified. An array of other indicators associated to pain experience was also identified.

Conclusion: The wide variety of tools identified for pain assessment suggests scarce evidence on the best tools. Due to the nature of cancer pain, the assessment of pain intensity alone provides a narrow view of the persistent pain experienced by children with cancer.
\end{abstract}

Keywords: pain; tool; child; cancer.

\section{Resumo}

Contexto: A dor persistente na criança com cancro apresenta particularidades que dificultam a sua avaliação.

Objetivos: Identificar instrumentos de avaliação de dor persistente e indicadores associados a esta experiência utilizados em crianças com cancro.

Método da revisão: Utilizando as bases de dados Medline e CINAHL, selecionaram-se estudos primários entre 2003 e 2013 que avaliaram a experiência de dor em crianças (0-18) com cancro. A seleção dos textos, a avaliação da qualidade metodológica e a extração e síntese dos dados foi realizada por dois investigadores, seguindo as orientações do The Joanna Briggs Institute.

Apresentação e interpretação dos resultados: Nos 16 estudos selecionados, identificaram-se 15 instrumentos de avaliação da dor e dois que avaliam também outros indicadores. Identificaram-se ainda outros indicadores considerados associados à experiência dolorosa. Conclusão: O elevado número de instrumentos identificados para avaliação da dor comprova a ausência de evidências sobre os melhores instrumentos. Dada a natureza da dor oncológica, parecenos que a avaliação exclusiva da intensidade é uma visão redutora das experiências de dor persistente das crianças com cancro.

Palavras-chave: dor; escala; criança; cancro.

\footnotetext{
*Ph.D., Coordinating Professor, Nursing School of Coimbra, Coimbra, Portugal [batalha@esenfc. pt]. Address for correspondence: Av. Bissaya Barreto - Ap. 7001, 3046-853, Coimbra, Portugal. Contribution to the article: methodological conception and design; selection of articles for analysis; analysis of the articles' methodological quality; article writing; critical content review.
** Ph.D., Coordinating Professor, Nursing School of Coimbra, Coimbra, Portugal [amfernandes@ esenfc.pt]. Contribution to the article: methodological conception and design; analysis and interpretation of articles; article writing; critical content review.

*** BScN, Research Grant Holder, Nursing School of Coimbra, Coimbra, Portugal. Research Grant funded by the Foundation for Science and Technology [dicatarinafcampos@ hotmail.com] Contribution to the article: methodological conception and design; search and selection of articles for analysis; analysis of the articles' methodological quality; article writing.
**** MSc, Adjunct Professor, Nursing School of Coimbra, Coimbra, Portugal [aperdigao@esenfc. $\mathrm{pt}$. Contribution to the article: critical content review.
}

\section{Resumen}

Contexto: El dolor persistente en niños con cáncer tiene características que complican su evaluación.

Objetivos: Identificar las herramientas de evaluación del dolor persistente y los indicadores asociados con esta experiencia utilizados en niños con cáncer.

Método de revisión: En las bases de datos Medline y CINAHL, se seleccionaron estudios primarios entre 2003 y 2013 que evaluaron la experiencia del dolor en niños (0-18 años) con cáncer. La selección de los textos, la evaluación de la calidad metodológica y la extracción y síntesis de los datos las realizaron dos investigadores de acuerdo con las directrices del Instituto Joanna Briggs.

Interpretación de los resultados: En los 16 estudios seleccionados se identificaron 15 herramientas para evaluar el dolor y dos para evaluar también otros indicadores. Asimismo, se identificó una serie de indicadores asociados a la experiencia dolorosa.

Conclusión: La amplia gama de herramientas identificadas para evaluar el dolor demuestra que no hay evidencias sobre los mejores instrumentos. Por la naturaleza del dolor en el cáncer, consideramos que la evaluación exclusiva de la intensidad supone una visión estrecha de las experiencias de dolor persistente en los niños con cáncer.

Palabras clave: dolor; escala; niño; chancro.

Received for publication: 23.01 .14

Accepted for publication: 15.10 .14 


\section{Introduction}

Cancer disease is a significant cause of pain in children, either due to the disease itself or the associated procedures and treatments (Gameiro, 2012). The longitudinal analysis of the prevalence of pain in these children showed that, over a year, all of them had experienced pain at least once (Van, Munoz, Riggs, Bava, \& Savedra, 2012). This was a symptom of the clinical presentation at diagnosis in, approximately, half of the cases (Ljungman, Gordh, Sorensen, \& Kreuger, 2000).

Several epidemiological studies confirm that approximately $40 \%$ to $50 \%$ of children with cancer experience pain (Forgeron, Finley, \& Arnaout, 2006; Jacob, McCarthy, Sambuco, \& Hockenberry, 2008; Miller, Jacob, \& Hockenberry, 2011) and approximately 20\% report severe pain (Jacob et al., 2008). Indeed, within the clinical presentation of paediatric cancer, pain emerges as one of the most common symptoms, and as part of a constellation of physical symptoms (Ameringer, 2010; Miller et al., 2011; Roth-Isigkeit, Thyen, Stoven, Schwarzenberger, \& Schmucker, 2005; Yeh et al., 2008).

Despite this evidence, many children do not receive adequate relief (Forgeron et al., 2006), which may be a result of an inaccurate diagnosis of pain (Jacob, Hesselgrave, Sambuco, \& Hockenberry, 2007). Unlike acute pain, persistent pain, which is invariably present in children with cancer, is not always accompanied by physiological symptoms. The assessment of pain in its various dimensions, as well as the effects accompanying it, is a key task (McGrath et al., 2008).

The indicators associated with the experience of pain refer to domains assessed simultaneously with pain experience and they were defined by the Pediatric Initiative on Methods, Measurement and Pain Assessment in Clinical Trials (Ped-IMMPACT) as follows: global satisfaction with treatment, symptoms and side effects, physical functioning, emotional functioning, role functioning, sleep and economic factors (McGrath et al., 2008).

Although these domains are defined, no reference is made to the most suitable assessment instruments or methods. We are unaware of studies which may have identified, in a systematic way, pain assessment tools and indicators associated with pain. The questions which guided this review were: Which are the persistent pain assessment tools used in children with cancer?; and Which indicators associated with the experience of pain in children with cancer are being assessed?.

The purpose was to identify the most commonly used persistent pain assessment tools and the indicators associated with the experience of pain, which are most commonly assessed in children with cancer.

\section{Systematic review method}

The following eligibility criteria were used: quantitative or qualitative primary studies which used pain assessment tools and/or other indicators associated with the experience of pain in children with cancer (0-18 years); children undergoing treatment or out of treatment, at any stage of the disease, inpatients or outpatients; and studies published in Spanish, French, English and Portuguese.

The following studies were excluded: studies about paediatric patients with cognitive impairment; assessment of pain associated with invasive procedures (peripheral venous catheterization, central venous catheterization, lumbar puncture, myelogram), paediatric and/or oncology data; and full text inaccessible.

\section{Search strategy and identification of studies}

In order to assess the relevance of this review, an exploratory search was performed in CINAHL and Medline to identify reviews on this topic. The body of studies for this review was obtained through a search in CINAHL and Medline databases, using the search engine of EBSCO. The search expression used was: (TX (pain assessment) OR TX (pain management) OR TX (pain measurement) OR TX (pain experience)) AND (SU (cancer)) AND (TX (child)). The search was limited to studies published between August, 2003, and August, 2013. The bibliographical references of the studies considered for inclusion were manually reviewed to identify additional studies.

The studies were identified in three stages: title reading; abstract reading; and full-text reading. The studies were independently selected by two researchers and any disagreements were resolved through consensus. 
Assessment of the methodological quality of the studies

The assessment of the methodological quality of the studies was performed using the Critical Appraisal Checklist for Descriptive/Case Series proposed by The Joanna Briggs Institute (2014).

Two reviewers assessed the articles independently and any disagreements on the analysis were resolved through consensus.

Due to the lack of guidelines for the application of the study quality assessment grid, the following criteria were adopted: low quality if less than $50 \%$ of the items are met, moderate quality if 50\% to $75 \%$ are met and high quality when more than $75 \%$ of the items are met.

\section{Data extraction}

Data extraction was performed by two researchers, following a standardized method: identification of the study, characteristics of the sample (country of origin, size, age group, type of cancer and treatment phase), data collection site and main results (pain assessment tools and/or indicators associated with the experience of pain).

\section{Data synthesis}

For data synthesis, a descriptive summary with the identification of the study, country of origin, type of study, studied sample and pain assessment tools and symptoms associated with cancer pain was drawn up. The synthesis of data related to pain assessment tools and associated symptoms was drawn up based on the target population, its characteristics, purpose of application and main findings of the study.

\section{Presentation of results}

The search identified 487 references. After reading the title, 34 studies were sent to abstract reading and 25 studies were kept for full-text reading. After the full-text reading, 16 primary studies were selected (Figure 1).

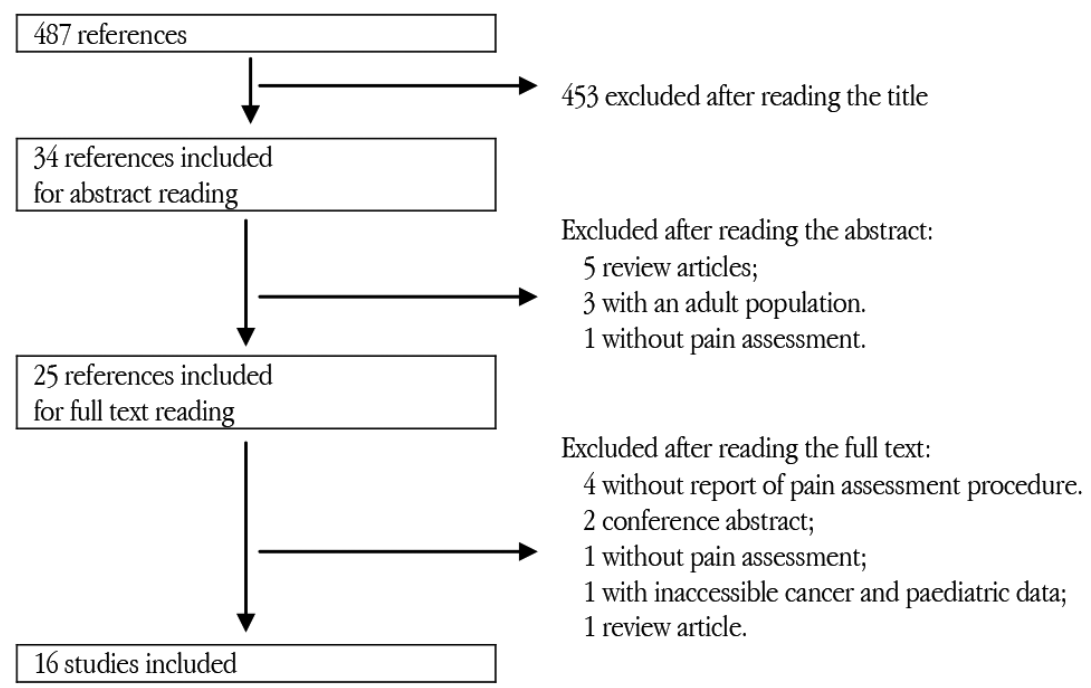

Figure 1. Diagram of the process of study selection.

According to the previously mentioned criteria for methodological quality assessment, 11 articles were considered to be of high quality and five of moderate quality. The bibliographic identification of the studies included is shown in Table 1. 
Table 1

Bibliographic identification of studies

\begin{tabular}{|c|c|}
\hline E1 & $\begin{array}{l}\text { Baggott, C., Gibson, F., Coll, B., Kletter, R., Zeltzer, P., \& Miaskowski, C. (2012). Initial evaluation of an electronic symp- } \\
\text { tom diary for adolescents with cancer. JMIR research protocols.1, 23. }\end{array}$ \\
\hline E2 & $\begin{array}{l}\text { Caran, E. M. M., Dias, C. G., Seber, A., \& Petrilli, A. S. (2005). Clinical aspects and treatment of pain in children and } \\
\text { adolescents with cancer. Pediatric Blood \& Cancer, 45, 925-932. }\end{array}$ \\
\hline E3 & $\begin{array}{l}\text { Docherty, S. L., Sandelowski, M., \& Preisser, J. S. (2006). Three months in the symptom life of a teenage girl undergoing } \\
\text { treatment for cancer. Research in nursing \& health, 29, 294-310. }\end{array}$ \\
\hline E4 & $\begin{array}{l}\text { Enskar, K., \& Von, E. L. (2008). Physical problems and psychosocial function in children with cancer. Paediatric nurs- } \\
\text { ing, 20, 37-41. }\end{array}$ \\
\hline E5 & $\begin{array}{l}\text { Forgeron, P. A., Finley, G. A., \& Arnaout, M. (2006). Pediatric pain prevalence and parents' attitudes at a cancer hospital } \\
\text { in Jordan. Journal of pain and symptom management, 31, 440-448. }\end{array}$ \\
\hline E6 & $\begin{array}{l}\text { Gedaly-Duff, V., Lee, K. A., Nail, L., Nicholson, H. S., \& Johnson, K. P. (2006). Pain, sleep disturbance, and fatigue in } \\
\text { children with leukemia and their parents: a pilot study. Oncology nursing forum, 33, 641-646. }\end{array}$ \\
\hline E7 & $\begin{array}{l}\text { Geeta, M. G., Geetha, P., Ajithkumar, V. T., Krishnakumar, P., Kumar, K. S., \& Mathews, L. (2010). Management of pain in } \\
\text { leukemic children using the WHO analgesic ladder. Indian journal of pediatrics, 77, 665-668. }\end{array}$ \\
\hline E8 & $\begin{array}{l}\text { Jacob, E., Hesselgrave, J., Sambuco, G., \& Hockenberry, M. (2007). Varia } \\
\text { talization in children with cancer. Journal of pediatric oncology nursing }\end{array}$ \\
\hline E9 & $\begin{array}{l}\text { Jacob, E., McCarthy, K. S., Sambuco, G., \& Hockenberry, M. (2008). Intensity, location, and quality of pain in Spanish- } \\
\text { speaking children with cancer. Paediatric nursing, 34, 45-52. }\end{array}$ \\
\hline E10 & $\begin{array}{l}\text { Linder, L. A., \& Christian, B. J. (2013). Nighttime sleep characteristics of hospitalized school-age children with cancer. } \\
\text { Journal for specialists in pediatric nursing: JSPN, 18, 13-24. }\end{array}$ \\
\hline E11 & $\begin{array}{l}\text { Miller, E., Jacob, E., \& Hockenberry, M. J. (2011). Nausea, pain, fatigue, and multiple symptoms in hospitalized children } \\
\text { with cancer. Oncology nursing forum, 38, E382-E393. }\end{array}$ \\
\hline E12 & $\begin{array}{l}\text { Mishra, S., Bhatnagar, S., Singh, M., Gupta, D., Jain, R., Chauhan, H., Goyal G.N. (2009). Pediatric cancer pain manage- } \\
\text { ment at a regional cancer center: implementation of WHO Analgesic Ladder. Middle East journal of anesthesiology, } \\
\text { 20, 239-244. }\end{array}$ \\
\hline E13 & $\begin{array}{l}\text { da Silva, F. C., Thuler, L. C. S., \& de Leon-Casasola, O. A. (2011). Validity and reliability of two pain assessment tools in } \\
\text { Brazilian children and adolescents. Journal of Clinical Nursing, 20, 1842-1848. }\end{array}$ \\
\hline E14 & $\begin{array}{l}\text { Van, C. L., Bossert, E., Beecroft, P., Adlard, K., Alvarez, O., \& Savedra, M. C. (2004). The pain experience of children with } \\
\text { leukemia during the first year after diagnosis. Nursing research, 53, 1-10. }\end{array}$ \\
\hline E15 & $\begin{array}{l}\text { Van, C. L., Munoz, C. E., Riggs, M. L., Bava, L., \& Savedra, M. (2012). Pain experience in children with advanced cancer. } \\
\text { Journal of pediatric oncology nursing, 29, 28-36. }\end{array}$ \\
\hline E16 & $\begin{array}{l}\text { Yeh, C. H., Chiang, Y. C., Chien, L. C., Lin, L., Yang, C. P., \& Chuang, H. L. (2008). Symptom clustering in older Taiwanese } \\
\text { children with cancer. Oncology nursing forum, 35, 273-281. }\end{array}$ \\
\hline
\end{tabular}

\section{Brief description of the studies}

Of the 16 selected studies, 15 were descriptive quantitative studies and one was a case study. Four studies only included children under six years old. In total, 694 children presenting different oncological pathologies were examined, although some studies focused on specific pathologies such as lymphoma (E3) and acute lymphoblastic leukaemia (E6), either in phase of treatment or out of treatment. In addition to pain assessment (intensity, location, quality and impact), all of the studies, with the exception of four, assessed indicators associated with the experience of pain (E5, E7, E9 and E13; Table 2). 
Table 2

Characteristics of the studies included

\begin{tabular}{|c|c|c|c|c|c|c|}
\hline \multirow{2}{*}{ Study } & \multirow{2}{*}{ Type } & \multicolumn{3}{|c|}{ Sample } & \multicolumn{2}{|l|}{ Results } \\
\hline & & $\mathrm{n}$ & Age (years) & Country & Tools & Associated indicators \\
\hline E1 & $\mathrm{D}$ & 10 & $13-21$ & USA & VAS; FPS-R; BD & $\begin{array}{l}\text { Fatigue; Mood; Nausea and vomiting; } \\
\text { Sleep; and Side effects. }\end{array}$ \\
\hline E2 & $\mathrm{D}$ & 135 & $1-20$ & Brazil & BFS; CCS; NR & Efficacy of analgesia. \\
\hline E3 & CS & 1 & 16 & USA & OS & $\begin{array}{l}\text { Anxiety; Stress; Nausea and vomiting; } \\
\text { and Sleep. }\end{array}$ \\
\hline E4 & $\mathrm{D}$ & 39 & $9.6 \pm 1.55$ & - & LSSC & $\begin{array}{l}\text { Fatigue; Psychosocial distress; Fam- } \\
\text { ily and social support; Role functioning; } \\
\text { Nausea; and Side effects. }\end{array}$ \\
\hline E5 & $\mathrm{D}$ & 35 & $2-17$ & Jordania & NS & - \\
\hline E6 & $\mathrm{D}$ & 9 & $8-16$ & USA & APPT & Fatigue and Sleep. \\
\hline E7 & $\mathrm{D}$ & 39 & $3-11$ & India & NR; WBFS & - \\
\hline E8 & $\mathrm{D}$ & 49 & $8-17$ & USA & APPT & Efficacy of analgesia; Activity; and Sleep. \\
\hline E9 & $\mathrm{D}$ & 54 & $7-12$ & USA & NR; APPT & - \\
\hline E10 & $\mathrm{D}$ & 15 & $8.8 \pm 2.3$ & USA & NR; WBFS & Sleep; Nausea and vomiting. \\
\hline E11 & $\mathrm{D}$ & 39 & $10-17$ & USA & MSAS & $\begin{array}{l}\text { Emotional functioning; Physical func- } \\
\text { tioning; and Side effects. }\end{array}$ \\
\hline E12 & $\mathrm{D}$ & 84 & $5-15$ & India & VAS & Efficacy of analgesia; and Side effects. \\
\hline E13 & $\mathrm{D}$ & 90 & $7-17$ & Brazil & FPS-R; FLACC & - \\
\hline E14 & $\mathrm{D}$ & 95 & $7-17$ & USA & PCT; PBO; APPT; DM & $\begin{array}{l}\text { Efficacy of analgesia; Functional status; } \\
\text { and Coping. }\end{array}$ \\
\hline E15 & $\mathrm{D}$ & 62 & $6-17$ & USA & MSAS; PBO; ABO & $\begin{array}{l}\text { Emotional functioning; Physical func- } \\
\text { tioning; and Side effects. }\end{array}$ \\
\hline E16 & $\mathrm{D}$ & 144 & $10-18$ & Taiwan & MSAS & $\begin{array}{l}\text { Emotional functioning; Physical func- } \\
\text { tioning; and Side effects. }\end{array}$ \\
\hline
\end{tabular}

D - Descriptive; CS - Case study; USA - United States of America; VAS - Visual Analogue Scale; FPS-R - Faces Pain Scale - Revised; BD - Body Diagram; BFS - Baby Faces Scale; CCS - Cartoon character's scale; NR - Numeric Rating Scale; OS - Oucher Scale; LSSC - Life Situation Scale for Children; NS - Nominal Scale; APPT - Adolescent Pediatric Pain Tool; WBFS - Wong-Baker Faces Scale; MSAS Memorial Symptom Assessment Scale; FLACC - Face, Legs, Activity, Cry, Consolability; PCT - The Poker Chip Tool; PBO - Preschool Body Outline; DM - Dot Matrix; ABO - Adolescent Body Outline

\section{Pain assessment tools}

\section{One-dimensional tools}

Fourteen one-dimensional tools assessing theintensity, location and evolution of the temporal pattern of pain were identified. The pain intensity assessment tools are the most prevalent ones in the table of results (E2, E7, E9, E10, E12, E13 and E 14). Out of the 10 pain intensity assessment tools, eight are self-report tools: four faces scales CCS; FPS-R; WBFS; OS; PCT; NR; VAS; NS. Of the two proxy rated pain scales identified, one was the behavioural observation scale FLACC and the other one was the BFS. Three tools used to assess the location of pain by means of body diagrams were identified: $\mathrm{PBO}$; $\mathrm{ABO}$; and BD. The DM scale assesses the evolution of the pattern of pain.

The scales most used were the NR (four studies) and the VAS, the FPS-R, the WBFS and the PBO (two studies each). There was a predominance of the use of faces scales in children under 6 years old, with the exception of the FPS-R (E13). The VAS and the NR scale were used in children over 5 years (old) (E9 and E12) and the FLACC scale was used in a study to assess its psychometric properties in children between the ages of 7 and 17 years (E13).

Pain intensity assessment scales made it possible to analyse the prevalence (diagnosis) of pain, quantify the painful experience and monitor the practices of pharmacological treatment regarding their effectiveness. Body diagrams to locate pain were used in children between 6 and 17 years old, allowing the identification of the most common pain locations (E12 and E14). The DM is a self-report instrument which measures pain in children older than 8 years. It consists of a dot matrix and a list of words describing the temporal dimension of 
pain. This tool was used in children aged between 7 and 17 years (E14; Table 2).

\section{Multidimensional tools}

A multidimensional pain assessment tool was identified in four studies, the APPT (E6, E8, E9 and E14; Table 2). This tool assesses pain as to its location, intensity and quality and has been used in children aged between 7 and 17 years (E9 and E14). The use of this self-report tool makes it possible to obtain data on the location of pain (use of a body diagram), the intensity of pain (word graphic rating scale) and the quality of pain (list of descriptors or words), which characterize the painful experience in a sensory, evaluative, affective and temporal dimension (E6, E8, E9 and E14).

\section{Cluster assessment}

MSAS and the LSSC were identified as tools assessing the intensity of pain, the associated symptoms and the social and psychological functioning of children with cancer (E4, E11, E15 and E 16; Table 2).

The MSAS was designed to obtain the child's selfreport (6-18 years) on the frequency, intensity and distress resulting from pain-related symptoms. It is composed of 30 items on a 4-point Likert scale in which the highest score corresponds to a higher frequency, intensity or distress (E15). This scale was used in three of the selected studies.

The ISSC was used in one study and allows identification of the physical problems and psychosocial functioning associated with the painful experience (E4). This scale was designed based on interviews to children with cancer and their parents.

\section{Other indicators}

In addition to pain assessment, 12 studies examined other indicators associated with the experience of pain. These indicators were assessed in cluster in four studies (E4, E11, E15 and E 6) and separately in eight studies. The side effects of treatment were also assessed in six studies (E1, E4, E11, E12, E15 and E16), while the efficacy of analgesia was assessed in four studies (E2, E8, E12 and E14). Some studies also assessed other aspects such as the physical and emotional functioning (E11,E15 and E16) and the psychosocial functioning (E4) using their own tools (Table 2).

It was possible to identify a range of indicators associated with the experience of pain which were assessed in children with cancer and complemented pain assessment. Among the most studied indicators are the side effects of treatments (seven studies), sleep (six studies), the analgesic efficacy, nausea and vomiting (five studies) and fatigue and physical and emotional functioning (four studies). Other indicators were also assessed, such as mood, anxiety, stress, psychosocial distress, family and social support, role functioning, activity throughout the day, functional status and coping mechanisms.

The indicators associated with the experience of pain were assessed based on different methods and instruments. Among them are the use of verbal, numerical and visual analogue scales, the actigraph (to assess the quality of sleep), the MSAS, Functional Status II, Pediatric Coping Inventory, Revised Children's Manifest Anxiety, Pediatric Nausea Assessment Tool, Pediatric Nausea, Vomiting and Retching Guide.

\section{Interpretation of results}

The identified studies revealed a range of pain intensity assessment tools (primary outcome measure) complemented with the assessment of other dimensions of the painful experience or associated indicators. The situation experienced by the child and family and the characteristics of cancer pain reinforce the importance assigned to the holistic assessment of persistent pain, thus overcoming the issue of its identification and poor description of the characteristics of its impact on the daily lives of children (Jacob et al., 2007).

\section{Pain assessment tools}

Most studies used pain intensity assessment scales, such as the faces scales (several types), the numerical scale, the nominal scale, the EVA, the FLACC and the PCT, which are used according to the age group, among other criteria (Ordem dos Enfermeiros, 2008). The location, quality and temporal pattern of pain were the least assessed characteristics, possibly due to the difficulty in obtaining them and making them objective (von Baeyer, 2009). The body diagrams are valid and reliable for use in children older than 7 years (von Baeyer, Lin, Seidman, Tsao, \& Zeltzer, 2011) and its use in children with cancer is useful to identify the most common locations of pain (Jacob et al., 2007; Jacob et al., 2008; Van et al., 2004). The pain descriptors in the APPT enable a qualitative assessment of the overall painful experience, assuming 
an integrative role in understanding the child's painful experience, thus making it possible for health care professionals to provide a more accurate diagnosis and treatment (Jacob et al., 2007; Jacob et al., 2008). The validity of these descriptors has been assessed in successive studies, determining its positive correlation with pain intensity and number of locations of pain identified in children aged over 8 years (Jacob et al., 2008).

The assessment of the temporal pattern of pain is another relevant data to guide treatment by characterizing the duration and variability of pain over time (Van et al., 2004). However, the validity and reliability of this tool, as well as its clinical usefulness, is not established.

The only multidimensional pain assessment scale identified was the APPT. This scale assesses the intensity of pain, its pattern of location and its qualitative characteristics (sensory, affective, evaluative and temporal). Its use helps children to talk about their experience of pain, allowing for a more detailed and accurate diagnosis (Gedaly-Duff, Lee, Nail, Nicholson, \& Johnson, 2006; Jacob et al., 2007; Jacob et al., 2008; Van et al., 2004) and, consequently, better treatment guidance. For example, the list of pain descriptors may indicate the presence of a neuropathic pain (burning, as an electric shock, numbness) that requires specific pharmacological treatment.

\section{Other indicators associated with the experience of pain}

The indicators associated with the experience of pain were assessed using different methods and instruments.

The MSAS and the LSSC were used to assess pain intensity, the associated symptoms and the social and psychological functioning of children with cancer. The first assesses the occurrence of pain, its intensity and the associated distress, enabling the establishment of the correlation between a constellation of simultaneous symptoms and pain (Miller et al., 2011; Van et al., 2012; Yeh et al., 2008). This helps implementing a treatment plan consistent with the overall experience of pain (multidimensional experience). In addition to identifying physical problems associated with the painful experience, the ISSC, as the MSAS, allows the assessment of the child's psychosocial functioning (Enskar \& Von, 2008), which, in some cases, can be of great value in understanding the child's experiences and subsequently implementing a multiprofessional treatment plan. It should be highlighted that the assessment of the child's physical functioning is not consensual because pain has a linear relationship with changes in physical performance (Palermo, 2000) and this assessment is more easily and simply performed using an EVA scale. Unlike the physical functioning, it has been suggested that the emotional functioning can regulate and/or predict the responses to pain (Eccleston \& Clinch, 2007).

The most frequently assessed indicators were the side effects of treatments, the changes in sleep patterns, the efficacy of analgesia, nausea and vomiting, fatigue, and physical and emotional functioning.

The symptoms associated with cancer and the side effects of the treatments, due to their frequency and impact on the child's daily life, require a valid and systematic assessment because of their importance for the therapeutic decision concerning analgesia (Caran, Dias, Seber, \& Petrilli, 2005; Docherty, Sandelowski, \& Preisser, 2006; Enskar \& Von, 2008; Miller et al., 2011; Mishra et al., 2009; Van et al., 2012; Yeh et al., 2008). The detailed diagnosis of the symptoms and side effects of treatments are an imperative for a preventive and sustained action based on interventions that help to control the constellation of symptoms associated with pain in these children (Kestler \& Lo Biondo-Wood, 2012). The use of MSAS to record these symptoms and/or side effects may be a valuable help in the diagnosis of the plethora of symptoms experienced by these children (Dupuis, Ethier, Tomlinson, Hesser, \& Sung, 2012).

The sleep pattern was assessed through numerical or visual analogue scales or the actigraph. There are no psychometric evidence for the use of numerical or visual analogue scales (Erickson, 2009). These scales assess the duration and quality of sleep and the number of awakenings in a retrospective way (Baggott et al., 2012; Jacob et al., 2007). The actigraph is a promising method to assess the sleep pattern in these children by allowing for an objective measurement of the duration and efficiency of sleep and the number of awakenings (Docherty et al., 2006; Gedaly-Duff et al., 2006; Linder \& Christian, 2013). Its clinical usefulness is confirmed, and its high cost is the only barrier to its clinical use (Erickson, 2009).

The assessment of the physical functioning, in which fatigue was the most commonly assessed symptom, 
determines the level of activity throughout the day and the ability to carry out the activities. Examining its relationship with pain helps establishing the need for analgesia (Gedaly-Duff et al., 2006; Jacob et al., 2007; Van et al., 2004; Van et al., 2012).

Other indicators were assessed, such as mood, anxiety, stress, psychosocial distress, family and social support, role functioning, activity throughout the day, functional status and coping mechanisms. Among these, the importance of identifying coping mechanisms should be highlighted, because its use is related to the success of pain relief (Batalha, 2010). The indicators most often associated with persistent pain in children are changes in the sleep pattern, mobilization, leisure and feeding (Agence Nationale d'Acreditation et d'Évaluation en Santé, 2000). Although symptoms such as nausea and vomiting were assessed, the dietary pattern was not specifically assessed, nor did the satisfaction with treatment, the economic impact and the role functioning related to pain.

\section{Conclusion}

Among the 17 methods used to assess pain in children with cancer, 14 one-dimensional tools were identified. Of these, 10 tools measure the intensity (BFS, CCS, OS, FPS-R, WBFS, FLACC, PCT, EVA, NR and nominal scale), three locate pain through a body diagram (PBO, $\mathrm{ABO}$ and $\mathrm{BD}$ ) and another tool assesses the temporal pattern (DM). Among the three multidimensional tools identified, one assesses pain in the dimensions of location, intensity and quality (APPT) and two assess pain and other symptoms associated with cancer (LSSC and MSAS). It was also possible to identify a set of indicators associated with the experience of pain (physical and emotional functioning, sleep and symptoms related to pain) that complement the assessment performed using pain assessment tools. None of the studies assessed the dietary pattern, the satisfaction with treatment, the economic impact and the role functioning in relation to pain.

The exclusion of studies involving paediatric patients with cognitive impairment and/or whose assessment of pain was associated with invasive procedures may be a limitation of this review.
Given the nature of cancer pain and its interference in the performance of daily activities, the exclusive assessment of pain intensity is a narrowing description of these children's experiences of pain.

The high number of tools identified to assess persistent paediatric cancer pain reveals the absence of clear evidence on the best way to assess pain. This limitation must not prevent the use of the available instruments. The studies show that the effort in understanding the experience of pain in children with cancer requires the simultaneous assessment of other symptoms, the side effects of the treatment, and its impact on the child's physical and psychosocial functioning. Multidimensional pain assessment tools should be continuously improved or combined in such a way as to obtain a multidimensional assessment of persistent pain in children with cancer, with clinical and research usefulness based on the domains recommended by the Ped-IMMPACT.

\section{Acknowledgments}

Study within the scope of the project "Experiences of pain in children with cancer: location, intensity and impact", funded by the Foundation for Science and Technology [PTDC/PSI-PCL /114652/2009]. We would like to thank the collaboration of Pain in Child Health (PICH).

\section{Sources of Funding}

Study within the scope of the project "Experiences of pain in children with cancer: location, intensity and impact", funded by the Foundation for Science and Technology [PTDC/PSI-PCL/114652/2009].

\section{References}

Agence Nationale d'Acreditation et d'Évaluation en Santé (2000). Evaluation et stratégies de prise en charge de la douleur aigue en ambulatoire chez lénfant de 1 mois à 15 ans. Paris: ANAES.

Ameringer, S. (2010). Barriers to pain management among adolescents with cancer. Pain Management Nursing, 11(4) $224-233$.

Batalha, L. (2010). Dor em pediatria: Compreender para mudar. Lisboa, Portugal: Lidel.

Dupuis, L. L., Ethier, M. C., Tomlinson, D., Hesser, T., \& Sung, L. (2012). A systematic review of symptom assessment scales in children with cancer. BMC Cancer, 12. 
Eccleston, C., \& Clinch, J. (2007). Adolescent chronic pain and disability: A review of the current evidence in assessment and treatment. Paediatrics Child Health, 12(2), 117-120.

Erickson, J. M. (2009). Approaches to measure sleep-wake disturbances in adolescents with cancer. Journal of Pediatric Nursing, 24(4), 255-269.

Gameiro, M. G. H. (2012). Adaptação dos adolescentes com cancro na fase de tratamento: Uma revisão da literatura. Revista de Enfermagem Referência, 3(8), 135-156.

Kestler, S. A., \& LoBiondo-Wood, G. (2012). Review of symptom experiences in children and adolescents with cancer. Cancer Nursing, 35(2), E31-E49.

Ljungman, G., Gordh, T., Sorensen, S., \& Kreuger, A. (2000). Pain variations during cancer treatment in children: A descriptive survey. Pediatric Hematology and Oncology, 17(3), 211-221.

McGrath, P. J., Walco, G. A., Turk, D. C., Dworkin, R. H., Brown, M. T., Davidson, K., . . Zeltzer, L. (2008). Core outcome domains and measures for pediatric acute and chronic/recurrent pain clínical trials: PedIMMPACT recommendations. The Journal of Pain, 9(9), 771-783.
Ordem dos Enfermeiros (2008). Dor - guia orientador de boa prática. Lisboa, Portugal: Autor.

Palermo, T. M. (2000). Impact of recurrent and chronic pain on child and family daily functioning: A critical review of the literature. Journal of Developmental and Behavioral Pediatrics, 21(1), 58-69.

Roth-Isigkeit, A., Thyen, U., Stoven, H., Schwarzenberger, J., \& Schmucker, P. (2005). Pain among children and adolescents: Restrictions in daily living and triggering factors. Pediatrics, 115(2), e152-e162.

The Joanna Briggs Institute (2014). Joanna Briggs Institute Reviewers' Manual: 2014 edition (Ed 2014). Australia: The Joanna Briggs Institute.

von Baeyer, C. L. (2009). Children's self-report of pain intensity: What we know, where we are headed. Pain Research \& Management, 14(1), 39-45.

von Baeyer, C. L., Lin, V., Seidman, L. C., Tsao, J. C., \& Zeltzer, L. K. (2011). Pain charts (body maps or manikins) in assessment of the location of pediatric pain. Pain Management, 1(1), 61-68. 
